\title{
Lipid Profile in Relation to Severity of Liver Diseases
}

\author{
Ahmed F. Gomaa ${ }^{a}$, Mahmoud A. Sharafeddin ${ }^{a}$, Amany M. AbdAllah ${ }^{b}$
}

\begin{abstract}
a Department of Internal Medicine, b Department of Family Medicine, Faculty of Medicine, Zagazig University, Egypt

Correspondence to: Ahmed F. Gomaa, Department of Internal Medicine, Faculty of Medicine, Zagazig University, Egypt.
\end{abstract}

E-mail:

gom3a20042000@yahoo.com

available online:14 May2020

\begin{abstract}
:
Background: Liver cirrhosis is a life-threatening condition. It is very prevalent in Egypt. Lipids are stored and metabolized in the liver. Liver cirrhosis has an essential influence on the lipid profile. Objectives: Evaluation of the lipid profile via assessing triglyceride (TG), total cholesterol, very low-density lipoprotein, low-density lipoprotein (LDL), and high-density lipoprotein (HDL) in cirrhotic patients and define its relationship to Child score. Patients and methods: This cross-sectional study was carried out in the Internal Medicine Department outpatient clinic, Zagazig University Hospital, Egypt. Ninety patients with liver cirrhosis were enrolled in the study. Fasting lipid profile was done. Comparison of the lipid profile in different Child classes in cirrhotic was done. Results: Total cholesterol, HDL, LDL, VLDL, and TG were compared in different childturcotte-pugh (CTP) classes. The data was analyzed on SPSS 21. Results showed significantly low levels of total cholesterol, HDL, LDL as the CTP class advances and also lower levels as compared with the control group. However, a statistically non-significant decrease in TG was observed. Conclusion: Total cholesterol, HDL, and LDL levels are significantly reduced in patients who develop liver cirrhosis and levels further decrease as the CTP classadvances.
\end{abstract}

Keywords: CTP score, lipid profile, liver disease

\section{Introduction:}

Liver cells play a serious task in the regulation of lipid metabolism. The principal location for lipoprotein and cholesterol synthesis is in the liver. In healthy individuals, a compound equilibrium is preserved between utilization, biosynthesis, and transfer of lipid fractions [1]. Many diseases that affect the parenchyma can lead 
to changes in the structure of lipoproteins and transport throughout the blood [2]. Nevertheless, in cirrhotic patients, the metabolism of lipid is changed such that glycogen stores are significantly diminished, contributing to malnutrition and biolysis [1]. The preceding studies have reported that cirrhotic patients have abnormal metabolism of lipids, especially reduction in cholesterol level and hypobetalipoproteinemia [3]. These alterations develop together with the progression of liver disease and may be considered as a prognostic marker for liver decompensation [4]. The maneuvers concerned with the decline of lipid particles in patients with cirrhosis are compound and needs multiple researches for a complete understanding. Protein microsomal triglyceride (TG) transfer protein - MTP], enzymatic (acylCoA: cholesterol acyltransferase), and apoprotein (Apo AI) reduction are considered to be linked to that changes [5-7]. Owing to the wide occurrence of liver disease in Egypt, we made this study to assess the profile of lipids in cirrhotic patients and to evaluate the relationship between lipid profile and the degree of cirrhosis.

\section{Materials and methods}

ign and study sample A cross-sectional study was done in the Internal Medicine Clinic, Zagazig University Hospital in the period from September to December 2017. The study design was approved by an institutional review board (IRB) of Faculty of Medicine, Zagazig University. Patients included in the study gave informed written consent in accordance with the Declaration of Helsinki.

\section{Inclusion criteria}

(1) Adult cirrhotic patients (18-65 years old).

(2) Those who accept participating in the study.

Exclusion criteria

(1) Associated comorbidity (diabetes mellitus, malignancy, uremia, gastrointestinal tract bleeding, previous history of dyslipidemia, and history of drugs such as antidiabetic or drugs for dyslipidemia)

(2) Patients presented with another liver dysfunction (Wilson's disease, hepatocellular carcinoma), with autoimmune diseases (rheumatoid arthritis systemic lupus), primary dyslipidemia were away from the study.

\section{Study process}

A questionnaire containing personal data such as age, sex, and cause of cirrhosis (e.g. viral hepatitis, hemochromatosis, Wilson's disease, drug-induced liver disease) was recorded for all patients. The diagnosis of liver cirrhosis was done via clinical symptoms and signs plus ultrasonographic features. 
The following division of the questionnaire included the presence of hepatic encephalopathy and ascites according to the Child criteria. Serum total cholesterol, triglycerides, and low-density lipoprotein (LDL) and high-density lipoprotein (HDL) were measured after $12 \mathrm{~h}$ overnight fasting. Finally, Child-Turcotte-Pugh was measured for every patient as an index for the degree of liver injury.

The lipid profile was categorized as follows:

hypotriglyceridemia was diagnosed based on TG less than $70 \mathrm{mg} / \mathrm{dl}$. Hypocholesterolemia was diagnosed based on VLDL less than 16 $\mathrm{mg} / \mathrm{dl}$, TC less than $100 \mathrm{mg} / \mathrm{dl}$, LDL less than $70 \mathrm{mg} / \mathrm{dl}$, or HDL less than $40 \mathrm{mg} / \mathrm{dl}$.

The normal values for triglycerides is less than $180 \mathrm{mg} / \mathrm{dl}$, cholesterol is less than 200 $\mathrm{mg} / \mathrm{dl}$, LDL cholesterol is less than 100 $\mathrm{mg} / \mathrm{dl}$, HDL cholesterol is greater than or equal to $40 \mathrm{mg} / \mathrm{dl}$ for men and greater than or equal to $50 \mathrm{mg} / \mathrm{dl}$ for the female gender. VLDL cholesterol is up to $30 \mathrm{mg} / \mathrm{dl}$ for the unisex gender and for all age groups [8].

Statistical analysis

Data analysis was performed using the software SPSS (statistical package for the social sciences; SPSS Inc., Chicago, Illinois, USA) version 21. Quantitative variables were described using their means and standard deviations. Categorical variables were described using their absolute frequencies. Kolmogorov-Smirnov (distribution-type) and Levene (homogeneity of variances) tests were used to verify assumptions for use in parametric tests. To compare means, one-way analysis of variance with Tukey's post-hoc test was used. To evaluate the association between categorical variables, Pearson's $\chi^{2-}$ test was used. The level statistical significance was set at $5 \%(\mathrm{P} \leq 0.05)$.

\section{Results:}

Most of the study participants were men $(58.9 \%)$. Their age ranged from 25 to 73 years with a mean age of $49.36( \pm \mathrm{SD}=11.19)$. All of our patients had postviral $\mathrm{C}$ cirrhosis. The largest percentages of cirrhotic patients had TG, HDL, LDL, and TC lower than the normal range. On the other hand, more than half of them had normal levels of VLDL cholesterol. About $40 \%$ of them had mean values of triglycerides, HDL, VLDL, LDL, and total cholesterol were $78.5,48,15,76$, and $132.5 \mathrm{mg} / \mathrm{dl}$, respectively (Tables 1 and 2). Lipid profile (total cholesterol, LDL, HDL, and triglycerides) were assessed for the severity of liver cirrhosis. Serum total, HDL, VLDL, LDL, and total cholesterol levels were significantly decreased with advancement of liver disease (Child A-C) and Tukey's test showed a statistically significant mean difference within the groups (Child B-A, CA, and C-B groups). Serum triglyceride level 
decreases with advancement of liver disease, but it was not statistically significant (Table 3 ).

Comparison was done using analysis of variance test: $*(\mathrm{P}<0.05)$ significant, $* *(\mathrm{P}<0.001)$ highly significant, and $(\mathrm{P}>0.05)$ not significant.

Table 1 Child-Pugh-Turcotte classification [8]

\begin{tabular}{lccc}
\hline Parameter & 1 point & 2 points & 3 points \\
\hline Serum bilirubin $(\mathrm{mg} / \mathrm{dl})$ & $>2$ & $2-3$ & $>3$ \\
Serum albumin $(\mathrm{g} / \mathrm{dl})$ & $>3.5$ & $3.5-2.8$ & $>2.8$ \\
Prothrombin time $(\uparrow \mathrm{s})$ & $1-3$ & $4-6$ & $>6$ \\
Ascites & None & Mild & Moderate \\
Encephalopathy & None & $1-2$ & $3-4$ \\
\hline
\end{tabular}

Child A, mild; Child B, moderate; Child C, severe liver injury; grades A, 5-6 points; grades B, 7-9 pints; grades C, 10-15 points.

Table 2 Sociodemographic, clinical, and laboratory data of the studied cases

\begin{tabular}{|c|c|c|c|}
\hline & $n(\%)$ & & $n(\%)$ \\
\hline Gender & & Child score & \\
\hline Female & $37(41.1)$ & A & $24(26.7)$ \\
\hline \multirow[t]{2}{*}{ Male } & $53(58.9)$ & B & $36(40)$ \\
\hline & & C & $30(33.3)$ \\
\hline Cause of cirrhosis & & $\mathrm{HDL}$ & \\
\hline Postviral & $90(100)$ & Normal & $31(34.4)$ \\
\hline Others & $0(0)$ & Decreased & $59(65.6)$ \\
\hline Triglycerides & & LDL & \\
\hline Normal & $40(44.4)$ & Normal & $42(46.7)$ \\
\hline Hypotriglyceridemia & $50(55.6)$ & Decreased & $58(53.3)$ \\
\hline VLDL & & Total cholesterol & \\
\hline Normal & $50(55.6)$ & Normal & $22(24.4)$ \\
\hline Decreased & $40(44.4)$ & Hypocholesterolemia & $68(75.6)$ \\
\hline Age & & $\mathrm{HDL}$ & \\
\hline Mean $\pm S D$ & $49.36 \pm 11.19$ & Mean $\pm S D$ & $46.79 \pm 14.06$ \\
\hline Median (range) & $49(25-73)$ & Median (range) & $48(18-76)$ \\
\hline Triglycerides & & VLDL & \\
\hline Mean \pm SD & $81.87 \pm 20.54$ & Mean $_{ \pm}$SD & $15.08 \pm 3.57$ \\
\hline Median (range) & $78.5(48-131)$ & Median (range) & $15(7-21)$ \\
\hline LDL & & Total cholesterol & \\
\hline Mean $\pm S D$ & $79.87 \pm 20.67$ & Mean \pm SD & $135.36 \pm 37.46$ \\
\hline Median (range) & $76(45-125)$ & Median (range) & $132.5(65-212)$ \\
\hline
\end{tabular}

LDL, low-density lipoprotein; VLDL, very low-density lipoprotein. 
Table 3 Comparison of lipid profile according to Child-Pugh score $(n=90)$ or severity of the liver disease

\begin{tabular}{lccccc}
\hline \multirow{7}{*}{$\begin{array}{c}\text { Child A } \\
\text { (mean } \\
\pm S D)\end{array}$} & $\begin{array}{c}\text { Child B } \\
\text { (mean } \\
\pm S D)\end{array}$ & $\begin{array}{c}\text { Child C } \\
(\text { mean } \\
\pm S D)\end{array}$ & $F$ & $P$ \\
\hline Triglycerides & 84.04 & 79.58 & 74.33 & 4.36 & 0.139 \\
& \pm 19.79 & \pm 20.17 & $\pm 18.45^{*}$ & & \\
HDL & 50.25 & 48.53 & 37.67 & 12.51 & $<0.001^{* *}$ \\
& \pm 18.9 & \pm 11.71 & $\pm 13.4^{*}$ & & \\
VLDL & 16.08 & 14.311 & 13.33 & 7.87 & $0.017^{*}$ \\
& $\pm 3.26^{*}$ & \pm 3.43 & \pm 3.65 & & \\
LDL & 98.38 & 74.61 & 69.2 & 15.03 & $<0.001^{* *}$ \\
& $\pm 16.03^{*}$ & \pm 16.03 & \pm 19.2 & & \\
Total & 174.62 & 134 & 106.07 & 26.65 & $<0.001^{* *}$ \\
cholesterol & \pm 28.43 & \pm 22.17 & \pm 27.02 & & \\
\hline
\end{tabular}

$\mathrm{HDL}$, high-density lipoprotein; LDL, low-density lipoprotein; VLDL, very low-density lipoprotein.

\section{Discussion:}

Liver cirrhosis is a prevalent disease in Egypt. In our study, we studied the relation between lipid parametersin cirrhotic patients and its relation to the degree of liver disease as evaluated by the Child-Pugh scoring. Our study determined that persons with liver cirrhosis had lower lipid levels including all five studied parameters (total cholesterol, TG, LDL, VLDL, and HDL). Serum LDL, HDL, VLDL, and total cholesterol were significantly decreasing with advancement of liver cirrhosis. Triglycerides level was also decreasing with increasing Child-Pugh scoring, yet was not significant. The liver plays a chief task in regulating the formation, breakdown, and in storing the lipoproteins and cholesterol. Total cholesterol plus lipoproteins had been shown to reduce with the increase of fibrosis and, more, with the development of liver cirrhosis. These changes in lipid profile can be used to evaluate prognosis in patients with liver cirrhosis $[4,5]$. A decrease in total cholesterol serum values is supposed to be the result of reduction in the formation or incomplete obstruction of the same esterification maneuvers, most probably due to a reduction in the formation of cholesterol acyltransferase enzyme [5-7,9]. Reduced VLDL values were accompanied by deficiencies in the microsomal triglyceride transfer protein and an incomplete suppression of cholesterol synthesis [10]. The synthesis of LDLs is positively associated with the synthesis of very LDLs and, when the metabolismis disrupted, the other downstream lipid parameters also change [11]. The reduction in HDLs values proposes that there is a powerful association between prognosis and reduced formation of apoprotein AI, the main HDL lipoprotein [12]. The prognosis of liver cirrhosis relays on the cause, severity of the disease, presence of another disease, and the complications. Numerous laboratory and clinical assessing parameters have been established to help in staging liver illness. The MELD and Child scores are the most broadly used system [13].

Many studies agreed with ours. In two studies in Pakista [14,15], they found that total cholesterol, HDL, and LDL levels are significantly reduced in patients who develop liver cirrhosis and levels further decrease as the child-turcotte-pugh (CTP) class advances. Vere et al. [16] showed in their study that 
cirrhosis decreases lipid levels. Bassani et al. [17] in their cross-sectional study on 314 cirrhotic patients found that a decrease in the lipid profile in cirrhotic patients due to $\mathrm{HCV}$ infection and/or alcoholic liver disease was significantly correlated with the MELD and Child-Pugh scores. These findings recommend that the lipid profile may be considered a valuable method in assessing liver disease. Ghadir et al. [4] found that (total cholesterol, TG, HDL, LDL) were significantly inferior in patients with cirrhosis than in the comparison group and the level of reduction in the serum total cholesterol, LDL, HDL, and (but not TG) had a powerful correlation with the degree of liver disease. Our study had multiple limitations. The results were collected from one center, with a limited number of patients and without the presence of a control group making it difficult to compare our findings with the results from other studies, although the absence of the control group did not worry the proposed data during analysis from the view of patients with cirrhosis. With that design of the study, it was difficult for calculating the data in a prognostic manner. But the results confirmed the value for evaluating the lipid profile in the long term in cirrhotic patients.

\section{Conclusion}

The decrease in lipid profile in HCV-induced liver cirrhosis was strongly associated with the degree of liver injury measured by the Child score. Our data advocated that the lipid parameters may be considered as a supporting method in appraising hepatic illness. It was strongly required for the performance of larger studies to confirm its applicability in cirrhotic patients due to other causes. It is consequently concluded that the amount of decrement in T. cholesterol, HDL, and LDL in cirrhotic patients is according to the progression of cirrhosis. It is recommended that lipid profile should be done in all cirrhotic patients.

\section{References:}

1 Bassendine MF, Sheridan DA, Bridge SH, Felmlee DJ, Neely RD. Lipids and HCV. Semin Immunopathol 2013; 35:87-100.

2 Studenik P. Lipid disorders in liver diseases. VnitrLek 2000; 46:547-548.

3 Napolitano M, Giuliani A, Alonzi T, Mancone C, D’Offizi G, Tripodi M, et al. Very low density lipoprotein and low density lipoprotein isolated from patients with hepatitis $\mathrm{C}$ infection induce altered cellular lipid metabolism. J Med Virol 2007; 79:254258.

4 Ghadir MR, Riahin AA, Havaspour A, Nooranipour M, Habibinejad AA. The relationship between lipid profile and severity of liver damage in cirrhotic patients. Hepat Mon 2010; 10:285-288.

5 Jiang M, Liu F, Xiong WJ, Zhong L, Xu W, Xu F, et al. Combined MELD and blood lipid level in evaluating the prognosis of decompensated cirrhosis. World J Gastroenterol 2010; 16:1397-1401. 
6 Nashaat EH. Comparative study of serum lipid profile between chronic hepatitis C Egyptian patients and normal controls and the effect of viral eradication on lipids profile. Report Opinion 2010; 2:14-20.

7 Tsai MH, Peng YS, Chen YC, Lien JM, Tian YC, Fang JT, et al. Low serum concentration of apolipoprotein A-I is an indicator of poor prognosis in cirrhotic patients with severe sepsis. J Hepatol 2009; 50:906-915.

8 Jacobson TA, Ito MK, Maki KC, Orringer CE, Bays HE, Jones PH, et al. National lipid association recommendations for patient centered management of dyslipidemia: part 1-full report. J Clin Lipidol 2015;9:129-169.

9 Schiff ER, Sorrell MF, Maddrey EC. Schiff's Diseases of the Liver. $9^{\text {th }}$ Edition Lippincott, Williams and Wilkins. Lancet 2008; 371:838-851.

10 Mirandola S, Bowman D, Hussain MM, Alberti A. Hepatic steatosis in hepatitis $\mathrm{C}$ is a storage disease due to $\mathrm{HCV}$ interaction with microsomal triglyceride transfer protein (MTP). Nutr Metab (Lond) 2010; 7:13.

11 Petit JM, Benichou M, Duvillard L, Jooste V, Bour JB, Minello A, et al. Hepatitis C virus associated hypobetalipoproteinemia is correlated with plasma viral load, steatosis, and liver fibrosis. Am J Gastroenterol 2003;98:1150-1154.
12 Habib A, Mihas AA, Abou-Assi SG, Williams LM, Gavis E, Pandak WN, et al. High-density lipoprotein cholesterol as an indicator of liver function and prognosis in noncholestaticcirrhotics. Clin Gastroenterol Hepatol 2005;3:286-291.

13 Inaba K, Barmparas G, Resnick S, Browder T, Chan LS, Lam L, et al. The Model for End-Stage Liver Disease score: an independent prognostic factor of mortality in injured cirrhotic patients. Arch Surg 2011;146:1074-1078.

14 UlHaq MI, Salim A, Malik K, Dilshad A, Amin J, Kamal A. Correlation of Child-Pugh class of cirrhosis and lipid profile. Proceeding SZPGMI 2016;30:19-23.

15 Subhan F, Khan I, Arif R, Khan A. Serum lipid profile as an indicator of the severity of liver damage in cirrhotic patients. Rawal Med J 2012; 37:387-389.

16 Vere CC, Streba CT, Streba L, Rogoveanu I. Lipid serum profile in patients with viral liver cirrhosis: Med Princ Pract 2012; 21:566-568.

17 Bassani L, Fernands S, Raimundo F, Marroni CA, Gonzalez MC, Harter DL. Lipid profile of cirrhotic patients and its association with prognostic scores: a cross-sectional study. Arq Gastroenterol 2015; 52:210215.

To cite this article: Ahmed F. Gomaa, Mahmoud A. Sharafeddin, Amany M. AbdAllah. Lipid Profile in Relation to Severity of Liver Diseases. BMFJ 2020;37(1):319-325 